\title{
NÍVEIS DE CONCENTRADO NA FASE DE TERMINAÇÃO EM CONFINAMENTO PARA NOVILHOS PREVIAMENTE MANTIDOS EM PASTAGEM NATIVA OU CULTIVADA ${ }^{1}$
}

\author{
CONCENTRATE LEVELS DURING FEEDLOT FINISHING FOR STEERS \\ PREVIOUSLY KEPT ON NATIVE OR CULTIVATED PASTURE
}

\author{
Carlos Alberto Torrel de Bail ${ }^{2}$ Ivan Luiz Brondani ${ }^{3}$ João Restle ${ }^{4}$
}

RESUMO

O estudo foi conduzido no Departamento de Zootecnia, Universidade Federal de Santa Maria-RS de junho a outubro de 1995. O objetivo foi avaliar o desempenho de novilhos que iniciaram o confinamento com $270 \mathrm{~kg}$ (mantidos em pastagem nativa durante o período de crescimento dos doze aos vinte meses) ou $340 \mathrm{~kg}$ (mantidos em pastagem cultivada), submetidos a dois níveis de concentrado, $45 \%$ (alto) ou $30 \%$ (baixo) da dieta (MS). Os tratamentos foram: T1, novilhos do campo nativo, relação volumoso:concentrado $70: 30$ (baixo); $T 2$, novilhos do campo nativo, relação volumoso:concentrado 55:45 (alto); T3, novilhos da pastagem cultivada, relação volumoso:concentrado 70:30 (baixo); e T4, novilhos da pastagem cultivada, relação volumoso:concentrado 55:45 (alto). O volumoso foi a silagem de milho. O concentrado incluiu milho grão triturado, farelo de soja, sal comum e calcário calcítico. A dieta dos quatro tratamentos continham $14 \%$ de proteína bruta. Foram usados 34 novilhos com idade média de 20 meses. $O$ delineamento experimental foi $o$ inteiramente casualizado, com quatro tratamentos em um esquema fatorial de $2 \times 2$ (dois pesos iniciais $x$ dois níveis de concentrado). Foram avaliados o consumo de matéria seca médio diário (CMS), ganho de peso médio diário (GMD) e conversão alimentar (CA). O CMS expresso em percentagem de peso vivo foi maior nos novilhos provenientes do campo nativo $(2,48 \%)$ do que nos de pastagem cultivada (2,17\%). Novilhos provenientes do campo nativo tiveram um GMD 20\% superior ao daqueles da pastagem cultivada (1,30 vs 1,08kg). GMD também foi maior para os novilhos com maior nível de concentrado $(1,30 \mathrm{~kg})$ que para aqueles com baixo nível (1,08kg). A CA dos novilhos do campo nativo e da pastagem cultivada foram respectivamente de 6,57 e 7,98, enquanto para os níveis baixo e alto de concentrado os valores foram de 7,8 e 6,75, respectivamente.
Palavras-chave: confinamento, bovinos de corte, ganho de peso compensatório, níveis de concentrado.

\section{SUMMARY}

The study was conducted at the "Departamento de Zootecnia, Universidade Federal de Santa Maria, RS”, from June to October, 1995. The objective was to evaluate the performance of steers beginning the feedlot with $270 \mathrm{~kg}$ ( kept on native pasture during the growth period from twelve to twenty months) or $340 \mathrm{~kg}$ (kept on cultived pasture during the growth period), submitted to two levels of concentrate $45 \%$ (high) or $30 \%$ (low) in the diet (DM basis). The treatments were: T1 Steers from native pasture, roughage:concentrate relation 70:30 (low); T2 Steers from native pasture, roughage:concentrate relation 55:45 (high); T3 Steers from cultivated pasture, roughage:concentrate relation 70:30 (low); T4 Steers from cultivated pasture, roughage:concentrate relation 55:45 (high). The roughage was corn silage. The concentrate included grinded corn, soybean meal, salt and limestone. The diets of the four treatments contained $14 \%$ of crude protein. Thirty-four Charolais, Nellore steers and their crosses with an average age of 20 months were used. The animals were taken from the herd of the "Departamento de Zootecnia". The experimental design was the completely randomized, with four treatmens in a factorial scheme $2 \times 2$ (two initial weights $x$ two concentrate levels). The average daily dry matter intake $(A D M I)$, average daily weight gain $(A D G)$ and feed conversion (FC) were evaluated. ADMI expressed in percentage of live weight was higher for steers from native pasture $(2.48 \%)$ than from cultivated pasture $(2.17 \%)$. Steers that came from native pasture had $20 \%$ higher ADG than those from cultivated pasture (1.30 vs $1.08 \mathrm{~kg})$. ADG was also higher for steers with high level of concentrate $(1.30 \mathrm{~kg})$ than for those with low level (1.08kg). FC

\footnotetext{
${ }^{1}$ Parte da dissertação de Mestrado apresentada pelo primeiro autor ao curso de Pós-graduação em Zootecnia da Universidade Federal de Santa Maria (UFSM).

${ }^{2}$ Zootecnista, Mestre em Zootecnia, Professor Substituto, Departamento de Zootecnia, UFSM.

${ }^{3}$ Zootecnista, Mestre em Zootecnia, Professor Assistente, Departamento de Zootecnia, Universidade Federal de Santa Maria (UFSM), 97105-900, Santa Maria, RS. E-mail: brondani@ccr.ufsm.br Autor para correspondência.

${ }^{4}$ Engenheiro Agrônomo, PhD., Professor Titular do Departamento de Zootecnia, UFSM.
} 
of steers from native or cultivated pasture were, respectively, 6.57 and 7.98, while for the low and high levels of concentrate the values were, respectively, 7.8 and 6.75 .

Key words: feedlot, beef cattle, compensatory growth, concentrate levels.

\section{INTRODUÇÃO}

No Rio Grande do Sul, a maior parte dos pecuaristas enfrentam problemas no seu rebanho em decorrência do inverno, pois tem a alimentação baseada no campo nativo. Nesse período, há uma paralisação no crescimento e por conseqüência redução do valor nutritivo, afetando o estado nutricional dos animais, o que acarreta perda de peso e, consequientemente, o comprometimento da lucratividade. A média de idade de abate dos bovinos do RS fica em torno de 3,5 anos (ANUALPEC, 1996), com isso, ocorre um giro mais lento do capital investido, comprometendo uma maior área de campo nativo para os mesmos, vindo a baixar a produção do rebanho de corte.

Com o objetivo de diminuir o tempo necessário para que os animais alcancem o peso de abate e para que possam ser comercializados na entressafra, contribuindo assim para melhorar a produtividade do rebanho, o produtor pode lançar mão do sistema de confinamento, que é mais uma alternativa que pode ser utilizada para melhorar o desenvolvimento desses animais, com um nível nutricional adequado (BRONDANI \& RESTLE, 1991). Com o confinamento, pode-se fazer uso de alimentos conservados como por exemplo a silagem de milho, que é o volumoso mais utilizado nesse sistema de engorda, devido a sua alta produção energética por unidade de área (BRONDANI, 1995). Segundo VILELA et al. (1986), tem sido mostrada a sua deficiência em atender a demanda protéica dos animais em terminação, principalmente os jovens. Por isso, faz-se necessário o uso de concentrado junto à silagem.

O produtor, na sua grande maioria, engorda os novilhos a campo, seja em campo nativo ou pastagem cultivada. Porém, no período de inverno, somente a pastagem cultivada fornece condições de engorda, sendo o clima favorável para o crescimento da mesma. Com o uso do confinamento e com uma forragem conservada (silagem), pode-se engordar os animais com mais segurança, independente do clima, e terminar os animais no período da entressafra.

Se o produtor fizer uso de animais de sobreano no confinamento, pode utilizar novilhos com diferentes pesos, principalmente devido aos níveis de alimentação diferenciados durante a fase de re- cria, (alimentados em campo nativo ou em pastagem cultivada). Aqueles animais melhor alimentados no período anterior apresentam um maior peso vivo, comparado com aqueles que sofreram restrição alimentar, o que pode indicar uma terminação mais cedo e representar melhores preços na comercialização (RESTLE, 1995).

Porém existe um fenômeno biológico, denominado por VERDE (1996) de crescimento compensatório no que se observa que aqueles restringidos na fase anterior (recria em campo nativo) podem responder com um maior ganho e melhor eficiência alimentar, mesmo que sejam mais leves do que aqueles que tiveram uma melhor alimentação. Assim sendo, o presente trabalho visou a avaliar o desempenho de novilhos confinados com diferentes pesos iniciais, provenientes de níveis alimentares distintos e submetidos a dois níveis de concentrado na dieta .

\section{MATERIAL E MÉTODOS}

O trabalho foi realizado no Setor de Bovinocultura de Corte do Departamento de Zootecnia da Universidade Federal de Santa Maria, no período de junho a outubro de 1995. Foram utilizados novilhos que na fase de recria, dos 12 aos 20 meses, foram mantidos em pastagem nativa, considerada condição de alimentação baixa ou pastagem cultivada, considerada condição de alimentação alta. Os tratamentos foram: $\mathrm{T} 1$, novilhos provenientes do campo nativo, relação volumoso:concentrado 70:30 (MS); T2, novilhos provenientes do campo nativo, relação volumoso:concentrado 55:45 (MS); T3, novilhos provenientes de pastagem cultivada, relação volumoso:concentrado 70:30 (MS); T4, novilhos provenientes de pastagem cultivada, relação volumoso: concentrado 55:45 (MS). As dietas de todos os tratamentos continham na matéria seca $14 \%$ de proteína bruta e o nível energético das dietas foi de 70,$34 ; 74,03 ; 70,57$ e 74,07\% de NDT, respectivamente, para T1, T2, T3 e T4. O concentrado foi composto de milho grão triturado, farelo de soja, sal comum, calcário calcítico e o volumoso usado foi a silagem de milho. Os animais foram arraçoados duas vezes ao dia, às 9 e 16 horas. $\mathrm{O}$ alimento foi fornecido à vontade, obedecendo a uma sobra média diária de $5 \%$ do alimento oferecido. Foram utilizados 36 novilhos provenientes do Setor de Gado de Corte da UFSM, pertencentes às raças Charolês, Nelore e suas cruzas com idade média de 20 meses. Os animais foram vermifugados no início do experimento. Foram utilizados 8 piquetes a céu aberto, contendo um comedouro de madeira por piquete e um bebedouro de concreto. Os animais foram adaptados às instalações e respectivas dietas durante 15 dias, 
iniciando o período experimental com 270kg de média (T1 e T2) e $340 \mathrm{~kg}$ (T3 e T4). Após terem atingido $420 \mathrm{~kg}$ de peso médio, os animais foram abatidos. Os novilhos foram pesados no início e no final do experimento, bem como a cada 28 dias. Quinzenalmente eram coletadas amostras do volumoso e dos componentes do concentrado, para análise em laboratório. $\mathrm{O}$ delineamento experimental foi $\mathrm{o}$ inteiramente casualizado, com quatro tratamentos, num esquema fatorial $2 \times 2$ (diferentes manejos $\mathrm{x}$ níveis de concentrado). Os dados coletados foram analisados pela análise de variância e testada a interação entre os níveis de concentrado e os diferentes pesos iniciais.

\section{RESULTADOS E DISCUSSÃO}

Na tabela 1, são apresentados os alimentos e teores de proteína bruta (PB) e energia digestivel (Mcal/kg MS) das dietas utilizadas. Na tabela 2, são apresentados os resultados da análise químicobromatológica dos alimentos utilizados nas dietas do experimento. A silagem de milho utilizada no experimento apresentou um teor de MS abaixo do ideal que seria de $33 \%$, embora em muitos trabalhos, como ZAGO et al. (1985) e de LAVEZZO $\boldsymbol{e t}$ al. (1987), observaram-se valores similares e até inferiores. A fração PB na silagem apresentou-se dentro dos padrões, concordando com a maioria dos trabalhos comparados, o mesmo aconteceu com o teor de fibra bruta $(25,05 \%)$. O teor de NDT da silagem

Tabela 1 - Composição percentual das dietas e seus teores de nutrientes digestíveis totais (NDT), proteína bruta (PB) e energia digestível (Mcal/kg MS).

\begin{tabular}{|c|c|c|c|c|}
\hline \multirow{2}{*}{ Ingredientes da dieta } & \multicolumn{4}{|c|}{ Tratamentos } \\
\hline & $\mathrm{T} 1$ & $\mathrm{~T} 2$ & $\mathrm{~T} 3$ & $\mathrm{~T} 4$ \\
\hline Silagem de milho & 70,0 & 55,0 & 70,0 & 55,0 \\
\hline Milho grão triturado & 15,6 & 30,9 & 16,1 & 31,1 \\
\hline Farelo de soja & 13,7 & 13,3 & 13,4 & 13,1 \\
\hline Calcário calcítico & 0,2 & 0,2 & 0,1 & 0,2 \\
\hline Sal comum & 0,5 & 0,6 & 0,4 & 0,6 \\
\hline NDT & 70,34 & 74,03 & 70,57 & 74,07 \\
\hline Proteína bruta & 14,1 & 14,2 & 14,0 & 14,1 \\
\hline Energia digestível da dieta, Mcal/kg MS & 3,095 & 3,257 & 3,105 & 3,259 \\
\hline
\end{tabular}

(62\%) foi intermediário aos teores relatados por VIEIRA et al. (1980) e PIMENTEL et al. (1996), que foram de 70,0 e $58,8 \%$, respectivamente.

Nas tabelas 3 e 4, são apresentados, respectivamente, os valores para consumo médio diário de matéria seca (Kg/animal) e consumo médio diário de matéria seca expressa em percentagem do peso vivo (CMSP). Segundo a análise de variâcia, não houve interação significativa entre nível de manejo na fase de recria e nível alimentar na fase de terminação para nenhuma das variáveis estudadas. Novilhos que durante a fase de recria, permaneceram em campo nativo e como conseqüência, apresentaram menor peso no início do confinamento, consumiram mais $(\mathrm{P}<0,0719)$ matéria seca por $100 \mathrm{Kg}$ de peso vivo $(2,48 \%)$ na fase de terminação, do que aqueles que previamente haviam permanecido em pastagem cultivada $(2,17 \%)$. Segundo PRESTON \& WILLIS (1970), está bem claro que animais que sofreram previamente uma restrição alimentar apresentam um incremento no consumo de alimentos durante o período em que ocorre o aumento no nível alimentar. No entanto, de acordo com HOGG (1991), a literatura é contraditória em relação ao incremento na quantidade de alimento que os animais consomem após ter ocorrido esse período de restrição alimentar. No presente experimento, os animais que permaneceram em campo nativo, na fase de recria, não tiveram restrição quantitativa de pasto e sim qualitativa. Ocorre que o campo nativo apresenta maiores teores de fibra e menor digestibilidade do que a pastagem cultivada, o que força o animal a um maior consumo de matéria seca para atender as suas exigências, resultando em um maior desenvolvimento e capacidade do trato digestivo. Isso deve ter sido uma das causas que influenciaram o maior consumo de matéria seca na fase de terminação. De acordo com HOGG (1991), não existe um mecanismo simples que domina a quantidade de alimento que o animal irá consumir. 
Tabela 3 - Médias e erros padrões para consumo médio diário de matéria seca (kg/animal),segundo os tratamentos.

\begin{tabular}{cccc}
\hline & \multicolumn{2}{c}{ Nível de manejo na fase de recria } & \\
\cline { 2 - 3 } $\begin{array}{c}\text { Nível alimentar na fase de terminação } \\
\text { (\% de concentrado) }\end{array}$ & \multicolumn{2}{c}{ Média } \\
\cline { 2 - 3 } & Pastagem nativa & Pastagem cultivada & \\
\hline & & & \\
\hline 30 & $8,24 \pm 0,581$ & $7,96 \pm 0,581$ & $8,1 \pm 0,411^{* *}$ \\
45 & $8,87 \pm 0,581$ & $8,94 \pm 0,581$ & $8,9 \pm 0,411^{* *}$ \\
Média & $8,55 \pm 0,411^{*}$ & $8,45 \pm 0,411^{*}$ & - \\
& & & \\
\hline
\end{tabular}

*Médias na linha ( $\mathrm{P}>0,2384)$.

** Médias na coluna $(\mathrm{P}>0,8724)$.

Conforme pode ser verificado na tabela 5 , o consumo de energia digestível em $\mathrm{Mcal} / 100 \mathrm{Kg}$ de peso vivo (CEDP) foi $13,8 \%$ maior nos animais que iniciaram o confinamento com menor peso, o que foi o resultado do maior CMSP (14,3\%). Também pode ser observado na tabela 5, que o CEDP aumentou em $14,5 \%$ quando o nível de concentrado na dieta aumentou de 30 para $45 \%$. Esse aumento no CMSP foi devido ao incremento de $9 \%$ no CMSP, embora não significativo, e do aumento na concentração energética da dieta (tabela 1). $\mathrm{O}$ aumento no CEDP ao elevar o nível de concentrado na dieta foi similar aos $13,7 \%$ verificado por SILVA (1999) quando aumentou o nível de concentrado de 35 para $45 \%$ na dieta que incluía como volumoso silagem de sorgo forrageiro, de novilhos alimentados em confinamento no período dos 20 aos 23 meses.

O GMD dos novilhos consta na tabela 6 . Verifica-se que tanto o nível de manejo na fase de recria como o nível de concentrado na dieta influenciaram significativamente $o$ GMD. Na média, o GMD foi $20,4 \%$ superior nos novilhos que haviam permanecido em pastagem nativa na fase de recria. Esse incremento foi igual ao verificado quando $\mathrm{o}$ nível de concentrado passou de 30 para $45 \%$. O maior GMD verificado nos animais mantidos previamente em pastagem nativa pode ser explicado pelo fenômeno biológico denominado de crescimento peso vivo $(\mathrm{kg} / 100 \mathrm{~kg} \mathrm{PV})$, segundo os tratamentos.

Médias na linha seguidas por letras diferentes diferem $(\mathrm{P}<0,0719)$.

* Médias na coluna $(\mathrm{P}>0,1922)$ compensatório (VERDE, 1996). Segundo HOGG (1991), o crescimento compensatório deve ser visto como um período de tempo transitório, seguindo um estresse nutricional, durante o qual o mecanismo homeostático responde ao incremento da disponibilidade de alimento. De acordo com o mesmo autor, durante essa transição grandes mudanças ocorrem no nível e atividade de hormônios e enzimas, requerimentos de mantença, consumo e digestibilidade do alimento, bem como no uso e a partição da energia e proteína. No presente experimento os animais que iniciaram o confinamento com o menor peso apresentaram um GMD 20,4\% superior aos que iniciaram com peso mais elevado. Essa diferença não é totalmente explicada pelo maior CEDP (13,8\%), portanto, além do maior consumo de matéria seca, outros fenômenos devem ter influenciados o GMD na fase de terminação, conforme é comentado por HOGG (1991). Por outro lado, os animais que, previamente, haviam sido mantidos em pastagem cultivada no período de recria manifestaram ganhos de peso inferiores, provavelmente, devido à composição do ganho. Esses animais, pelo fato de apresentarem maior peso ao iniciar o confinamento, estavam depositando mais gordura, portanto, fazendo ganhos de peso com maior concentração de energia, o que exige maior quantidade de energia

Tabela 4 - Médias e erros padrões para consumo médio diário de matéria seca em percentagem de

\begin{tabular}{|c|c|c|c|}
\hline \multirow{2}{*}{$\begin{array}{l}\text { Nível alimentar na fase de terminação } \\
\text { (\% de concentrado })\end{array}$} & \multicolumn{2}{|c|}{ Nível de manejo na fase de recria } & \multirow[b]{2}{*}{ Média } \\
\hline & Pastagem nativa & Pastagem cultivada & \\
\hline 30 & $2,39 \pm 0,111$ & $2,07 \pm 0,111$ & $2,23 \pm 0,089^{*}$ \\
\hline 45 & $2,57 \pm 0,111$ & $2,28 \pm 0,111$ & $2,43 \pm 0,089^{*}$ \\
\hline Média & $2,48 \pm 0,089^{\mathrm{A}}$ & $2,17 \pm 0,089^{\mathrm{B}}$ & - \\
\hline
\end{tabular}


Tabela 5 - Médias e erros padrões para consumo médio diário de energia digestível (Mcal/100kg peso vivo), segundo os tratamentos.

\begin{tabular}{|c|c|c|c|}
\hline \multirow{2}{*}{$\begin{array}{l}\text { Nível alimentar na fase de terminação } \\
\text { (\% de concentrado) }\end{array}$} & \multicolumn{2}{|c|}{ Nível de manejo na fase de recria } & \multirow[b]{2}{*}{ Média } \\
\hline & Pastagem nativa & Pastagem cultivada & \\
\hline 30 & $7,42 \pm 0,391$ & $6,43 \pm 0,391$ & $6,92 \pm 0,277 * *$ \\
\hline 45 & $8,38 \pm 0,391$ & $7,46 \pm 0,391$ & $7,92 \pm 0,277 * *$ \\
\hline Média & $7,90 \pm 0,277^{*}$ & $6,94 \pm 0,277 *$ & - \\
\hline
\end{tabular}

* Médias na linha $(\mathrm{P}<0,0708)$.

** Médias na coluna $(\mathrm{P}<0,0638)$.

consumida por $\mathrm{Kg}$ de ganho de peso. Essa diferença na deposição de gordura deve ter sido mais evidente no início do período de confinamento. Verifica-se que o efeito do nível de concentrado na dieta foi mais acentuado nos animais que iniciaram o confinamento com maior peso, nos quais, entre o nível de 30 e $45 \%$ de concentrado, a diferença no GMD foi de $300 \mathrm{~g}$. Já nos animais que iniciaram o confinamento com menor peso, a diferença no GMD foi de $120 \mathrm{~g}$ entre os dois níveis de concentrado. Constatase que a quantidade de energia consumida pelos animais, que iniciaram o confinamento com maior peso e que receberam $30 \%$ de concentrado na dieta, foi insuficiente para proporcionar um ganho de peso elevado. O aumento no GMD de $20 \%$, ao elevar o nível de concentrado de 30 para $45 \%$, foi causado principalmente pelo incremento do consumo de energia (tabela 5). SILVA (1999), utilizando grupos genéticos similares ao do presente experimento, alimentados com silagem de sorgo associado a 35 ou $45 \%$ de concentrado, verifi-

cou um incremento similar no GMD e que foi de $18,1 \%$. O maior GMD foi observado nos animais que iniciaram o confinamento com menor peso e que receberam $45 \%$ de concentrado na dieta. O GMD desse tratamento foi $46,2 \%$ superior ao daquele manifestado pelos animais que iniciaram o confinamento com maior peso e que receberam $30 \%$ de concentrado na dieta. Nota-se ainda, na tabela 6 , a tratamentos.

Médias na linha seguidas de letras diferentes diferem $(\mathrm{P}<0,0349)$.

Médias na coluna seguidas por letras diferentes diferem $(\mathrm{P}<0,0272)$. similaridade no GMD entre os animais que iniciaram o confinamento com menor e maior peso, e que receberam, respectivamente, 30 e $45 \%$ de concentrado na dieta. Como era de se esperar, o GMD dos animais de todos os tratamentos acompanhou o CEDP (tabela 5).

Nas tabelas 7 e 8 são apresentadas, respectivamente, as médias para conversão alimentar (Kg de MS consumida/Kg de ganho de peso) e eficiência energética (Mcal de energia digestível/Kg de ganho de peso). Os animais que sofreram restrição alimentar durante o período de recria e que iniciaram o confinamento com menor peso foram mais eficientes, pois consumiram menos matéria seca $(6,57$ vs $7,98 \mathrm{Kg} ; \mathrm{P}<0,0468)$ e menos energia digestível $(20,88$ vs $25,34 \mathrm{Mcal} ; \mathrm{P}<0,0482)$ por $\mathrm{Kg}$ de ganho de peso do que os animais que iniciaram o confinamento com maior peso. De acordo com PRESTON \& WILLIS (1971), em animais que sofreram a restrição alimentar, a melhor eficiência na utilização de alimentos durante o período em que aumenta o nível alimentar é uma consequiência do maior ganho de peso relativo ao peso corporal. A melhor eficiência alimentar e energética verificada nos animais com peso inicial menor em relação aos com peso inicial maior, pode ter sido causada por vários fatores. Entre esses fatores, podem-se citar as diferenças na composição de ganho, no consumo de

Tabela 6 - Médias e erros padrões para ganho de peso médio diário dos animais (kg), segundo os

\begin{tabular}{cccc}
\hline & \multicolumn{2}{c}{ Nível de manejo na fase de recria } & \\
\multirow{2}{*}{$\begin{array}{c}\text { Nível alimentar na fase de terminação } \\
(\% \text { de concentrado })\end{array}$} & & \\
\cline { 2 - 3 } & & & \\
& Pastagem nativa & Pastagem cultivada & Média \\
30 & $1,24 \pm 0,099$ & $0,93 \pm 0,099$ & $1,08 \pm 0,070^{\mathrm{B}}$ \\
45 & $1,36 \pm 0,099$ & $1,23 \pm 0,088$ & $1,30 \pm 0,066^{\mathrm{A}}$ \\
Média & $1,30 \pm 0,070^{\mathrm{A}}$ & $1,08 \pm 0,066^{\mathrm{B}}$ & - \\
& & & \\
\hline
\end{tabular}


Tabela 7 - Médias e erros padrões para conversão alimentar, (Kg de matéria seca consumida/Kg de ganho de peso), segundo os tratamentos.

\begin{tabular}{|c|c|c|c|}
\hline \multirow{2}{*}{$\begin{array}{l}\text { Nível alimentar na fase de terminação } \\
\text { (\% de concentrado) }\end{array}$} & \multicolumn{2}{|c|}{ Nível de manejo na fase de recria } & \multirow[b]{2}{*}{ Média } \\
\hline & Pastagem nativa & Pastagem cultivada & \\
\hline 30 & $6,65 \pm 0,495$ & $8,96 \pm 0,495$ & $7,80 \pm 0,350 *$ \\
\hline 45 & $6,50 \pm 0,495$ & $7,01 \pm 0,495$ & $6,75 \pm 0,350 *$ \\
\hline Média & $6,57 \pm 0,350^{\text {B }}$ & $7,98 \pm 0,350^{\mathrm{A}}$ & \\
\hline
\end{tabular}

Médias na linha seguidas por letras diferentes diferem $(\mathrm{P}<0,0468)$. ${ }^{*}$ Médias na coluna $(\mathrm{P}>0,1015)$.

energia, nos requerimentos de mantença e no crescimento de orgãos internos (PRESTON \& WILLIS, 1971; HOGG, 1991). Conforme pode-se verificar ainda nas tabelas 7 e 8 , não houve diferença significativa entre os níveis de concentrado, tanto para conversão alimentar $(\mathrm{P}>0,1015)$ como para eficiência energética $(\mathrm{P}>0,2382)$.

Um aspecto importante ao considerar o peso inicial do animal na terminação é sua relação com o período de alimentação necessário para atingir o peso de abate desejado (RESTLE, 1995). Considerando o mesmo peso final de $420 \mathrm{Kg}$ e os GMD obtidos pelos animais na fase de terminação, verifica-se que o número de dias necessários para atingir o peso estipulado foi de 121 e 110 dias para os novilhos que iniciaram o confinamento com $270 \mathrm{Kg}$ e que receberam, respectivamente, 30 ou $45 \%$ de concentrado. Já nos animais que iniciaram o confinamento com $340 \mathrm{Kg}$, o número de dias foi de 86 e 65 dias, respectivamente, para os níveis de concentrado de 30 e $45 \%$. Portanto, animais que iniciam o confinamento com menor peso necessitam um período mais longo de alimentação para atingir o peso de abate, o que representa maior quantidade de alimento consumido. A decisão para optar entre pastagem nativa ou cultivada na fase de recria deve se basear, principalmente, nos custos da pastagem cultivada e dos alimentos gastos no confinamento. $\mathrm{O}$ de peso), segundo os tratamentos.

Médias na linha seguidas por letras diferentes diferem $(\mathrm{P}<0,0482)$.

* Médias na coluna ( $\mathrm{P}>0,2382)$. tempo necessário para atingir o peso de abate tem uma implicação muito importante na comercialização dos animais. Acontece que o maior preço $\mathrm{pago} / \mathrm{Kg}$ de peso nos últimos anos, no Rio Grande do Sul, tem sido no período de 15 de julho a 31 de agosto. Para que o produtor possa se beneficiar desse maior preço, é necessário que o animal apresente o peso e acabamento exigidos pelo frigorífico, o que é mais rápido de ser atingido com animais que no início do confinamento apresentam peso mais elevado, mesmo recebendo um nível de concentrado mais baixo na dieta.

\section{CONCLUSÕES}

Restrição alimentar na fase de recria resulta em maiores consumos de matéria seca e de energia digestível durante a terminação de novilhos. Animais que sofrem restrição alimentar, na fase de recria, apresentam crescimento compensatório quando confinado para terminação, e os que recebem maior nível de concentrado, na fase de terminação, obtém maior ganho de peso médio diário. Animais com restrição alimentar, na fase de recria, são mais eficientes na fase de terminação, ao passo que aqueles que não passam por restrição alimentar atingem condição de abate mais cedo.

Tabela 8 - Médias e erros padrões para eficiência energética (Mcal de energia digestível/Kg de ganho

\begin{tabular}{cccc}
\hline & \multicolumn{2}{c}{ Nível de manejo na fase de recria } & \\
Nível alimentar na fase de terminação & & \\
\cline { 2 - 3 }$(\%$ de concentrado $)$ & & & \\
& & & \\
& & & \\
& & & \\
30 & $20,58 \pm 1,582$ & $27,83 \pm 1,582$ & $24,21 \pm 1,119^{*}$ \\
45 & $21,19 \pm 1,582$ & $22,85 \pm 1,582$ & $22,01 \pm 1,119^{*}$ \\
Média & $20,88 \pm 1,119^{\mathrm{B}}$ & $25,34 \pm 1,119^{\mathrm{A}}$ & \\
& & &
\end{tabular}




\section{REFERÊNCIAS BIBLIOGRÁFICAS}

ANUALPEC, Anuário estatístico da produção animal. São Paulo: FNP, 1996. 303p.

BRONDANI, I.L., RESTLE, J. Efeito das dietas contendo canade-açúcar ou silagem de milho no desempenho de novilhos em confinamento. Ciência Rural, Santa Maria, v. 21, n. 1, p. 129134, 1991.

BRONDANI, I.L. Alimentos volumosos. In: RESTLE, J. BRONDANI, I.L., PASCOAL, L.L., et al.. Curso sobre confinamento de bovinos de corte. Santa Maria: UFSM, 1995. p. $1-14$.

HOGG, B.W. Compensatory growth in ruminants. In: PEARSON, A.M., DUTSON, T.R. Growth regulation in farm animals. London: Elsevier science, 1991. Cap. 5. p. 103-128.

LAVEZZO, W., LAVEZZO, O E.N.M., NETO, O.C. Efeito do estágio de desenvolvimento do milho (Zea mays, L.) sobre a digestibilidade e consumo de suas silagens. In: REUNIÃO ANUAL DA SOCIEDADE BRASILEIRA DE ZOOTECNIA, 24, 1987, Brasilia, DF. Anais... Brasilia: Sociedade brasileira de Zootecnia, 1987. 427 p. p. 139.

PIMENTEL, J.J.O, COELHO, J.F., FILHO, S.V.C. et al. Consumo voluntário, composição quimica e valor nutritivo das silagens de milho e de sorgo. In: REUNIÃO ANUAL DA SOCIEDADE BRASILEIRA DE ZOOTECNIA, 33, 1996, Fortaleza, CE. Anais... Viçosa: Sociedade Brasileira de Zoo- tecnia, 1996.479 p. p. $379-381$.

PRESTON, T.R., WILLIS, M.B. Intensive beef production. Oxford: Pergamon, 1970. 544 p.

RESTLE, J. Confinamento de terneiros. In: RESTLE, J., BRONDANI, I.L., PASCOAL, L.L., et al.. Curso sobre confinamento de bovinos de corte. Santa Maria: UFSM, 1995. p. $47-63$

SILVA, N.L.Q. Terminação de novilhos em confinamento alimentados com silagens de dois hibridos de sorgo (Sorghum bicolor L. Moench) associados a três niveis de concentrado. Santa Maria-RS, 1999. 100 p. Dissertação (Mestrado em Zootecnia)- Curso de Pós-graduação em Zootecnia, Universidade Federal de Santa Maria, 1999.

VERDE, L.S. Crescimento compensatório. In: VERDE, L.S. Curso sobre crescimento e crescimento compensatório na produção animal. Santa Maria, 1996.

VIEIRA, P. de F., FARIA, V.P., ANDRADE, P. Valor nutritivo de três variedades de milho. Revista da Sociedade Brasileira de Zootecnia, Viçosa. n. 9, v. 1, p. 157-170, 1980.

VILELA, D., MELLO, R.P., VILLAÇA, H.A. Efeito da cama de aviário e da uréia na ensilagem do milho sobre o desempenho de vacas em lactação. Revista da Sociedade Brasileira de Zootecnia, Viçosa, v. 15, n. 1, p. 57-68, 1986.

ZAGO, C.P., OBEID, J.A., GOMIDE, J.A Desempenho de novilhos zebu alimentados com silagens consorciadas de milho (Zea mays, L.) com soja anual (Glicine $\max$ (L.) Merrill). Revista da Sociedade Brasileira de Zootecnia, Viçosa. v. 14, n. 14, p. 510-514, 1985.

Ciência Rural, v. 30, n. 1, 2000. 157 